exerted on a large mass of metal by a trace of another metal or metalloid-that is, by a quantity so small that it appears to be out of all proportion to the mass in which it is distributed.

I think it may safely be asserted that in no other branch of applied science has the operator to deal with quantities that are at once so vast and so mintute; and the course will not have proceeded far before you will recognise this fact.

It may be that the trace to be extracted is alone of value-as, for instance, the few grains of gold that can be profitably cxtracted from each ton of a material, which, though containing only one part of gold in five millions by volume, is thereby entitled to be regarded as an auriferous deposit that can be profit ably worked; or it may be the minute percentage of a metalloid which must be extracted in order that the physical properties of a large mass of metal may not be entirely altered.

[Numerous instances of the influence of small traces of metals and metalloids, including the following, were then given:- ]

In 1866 Graham showed, ${ }^{1}$ by experiments with which $\mathrm{I}$ had the privilege of being connected, that the presence of occluded gases in metals often exerts a marked influence on their molecular structure. In the case of iron he urged that metalluroists should study the effects of occluded gases, more especially carbonic oxide, the weight of which, according to his experiments, could not exceed the $\frac{1}{15}$ per cent. of the weight of iron in which it was present. The significance of such facts is now under consideration by a Committee of the Institution of Mechanical Engineers, ${ }^{2}$ and the question of the presence of gas in steel, either occluded or retained in the form of bubbles, is further being investigated by Chernoff, ${ }^{3}$ Müller, ${ }^{4}$ and others.

M. Nyst, of the Brussels Mint, has lately found that the presence of $\frac{15}{100}$ per cent. of silicon in standard gold will so affect its molecular grouping as to render it possible for a thin strip to bend by its own weight, as zinc would, in the flame of a candle.

The growing importance of physical research in connection with metallurgy is shown by the fact that physical methods are now constantly appealed to by those interested in metallurgy, more especially in the case of iron and steel. We are told, for instance, that the hardness of steel may be correctly inferred from a numerical determination of its coercive force ${ }^{5}$ it is sought to establish the actual nature of the change in the mode of existence of the carbon in steel that accompanies hardening by determining its thermo-electric properties $;{ }^{6}$ and the hope is held out ${ }^{7}$ to us that the time will soon come when boiler-makers will electrically test their plates, possibly by the aid of the inductionbalance, just as they now test them for ductility and tenacity. I can only add the expression of a belief that this powerful weapon of molecular research which Prof. Hughes has given us will yield good results in the hands of some of you.

The results of mechanical tests are also of the highest importance. Not long since the appearance of the fracture of a sample of metal was considered to afford trustworthy and suffi. cient evidence as to its nature and properties; but such rough methods bave given place, in the hands of Kirkaldy and others, to the rigorous physical and mechanical investigation to which metals must now be submitted as a matter of ordinary routine. The results, tabulated or plotted into curves, which mark the influence of each constituent or impurity, form permanent records of the greatest value. ${ }^{8}$

It has only been possible for me to indicate the more important conditions affecting the successful practice of metallurgy. I have traced the relation between technical and scientific workers; but there is yet another condition of somewhat recent growth. The enormous scale on which operations are now conducted renders it more necessary than formerly for those engaged in metallurgical enterprise to seek the aid of capitalists. The result is that a large share in the control of many important works falls to the non-scientific members of the Board of Directors, men of high commercial ability, but whose knowledge of the importance of scientific work is necessarily limited. It is true that

^ Phil. T'rans. 1866, p. 438.

First Report of the Committee on the Hardening, Tempering, and Annealing of Steel, 1879 .

3 "On the Structure of Cast Steel Ingots." Translated for the Institution of Mechanical Engineers by W. Anderson, C.E ( 1879 ).

${ }_{4}$ Berichte der deutschen chemischen Gesellschaft, $\times 879$, No. xii. 93 ; Glaser's Annalen fïr Gezverbe und Bautvesen, August, r 880, p. ${ }_{3} 8$.

5 Trève and Durassier, Comp. rend., t. lxxx. (1875); p. 799 ; Watten hofen, Fournal of the Iron and Steel Institute, 1879 , No. x, p. 305.

6 Barus, Phil. Mag. [5], vol, viii. p. 34 I.

7 W. H. Johnson, Chemical Nczes, vol. xlii. (1880), p. 70

$8 \mathrm{~V}$. Deshayes, "Classement et Emploi des Aciers" (Paris, r880); also Bull. Chem. Soc. tom. xxxi. (1879), p. 166 . they may recognise the necessity for scientific aid in the works with which they are connected, but they are too often unconscious of the labour and difficulty that are involved in the attainment of accurate scientific knowledge. I am convinced, however, that facts are gradually compelling them to recognise that the value of a metal may entirely depend on whether it does or does not contain a trace of impurity, and that the exact method of treatment to be adopted depends much on the character of the materials employed; they will therefore examine more carefully than they have hitherto done the qualifications of men to whom important duties are entrusted, and will insist that the services of-only adequately trained metallurgists shall be secured.

I shall have to direct your attention to the minute care with which details affecting commercial interests are now investigated $;^{1}$ and your success will further depend on the facility with which you are able to use the "tools of thought" furnished by chemistry, physics, and mechanics. Whether you will evei possess the tact and judgment necessary to direct such works as Dowlais with an army of Io,coo people, obviously depends on pers $>n a l$ qualifications which I can but little influence.

$I$ venture to hope that you will, by original research, add to the general advance of science, for, as the late Prof. Clifford has reminded us, what have often proved to be the most useful parts of science have been investigated for the sake of truth, and not for their usefulness.

Dr. Percy found metallurgy practised in this country mainly as an empirical art. He may well feel, to borrow the words of an old writer, that in his hands "the business of metallurgy and essaying has not only been illustrated but also improv'd, amended, and enrich'd"; for his works contain a record of it progress, his teaching and researches have secured it a scientific basis, and he has trained a body of scientific workers, in whose hands the immediate future of metallurgy to a great extent rests. Bearing in mind how much the progress of our science means to England, I cannot but be conscious that, in attempting to continue this work, I undertake a grave responsibility.

\section{ON AN EXPERIMENTAL ILLUSTRATION OF MINIMUM ENERGY ${ }^{2}$}

THIS illustration consists of a liquid gyrostat of exactly the same construction as that described and represented by the annexed drawing, repeated from NATURE, February I, I877, p. 297, 298, with the difference that the figure of the shell is prolate instead of oblate. The experiment was in fact conducted with the actual apparatus which was exhibited to the British Association at Glasgow in 1876 , altered by the substitution of a

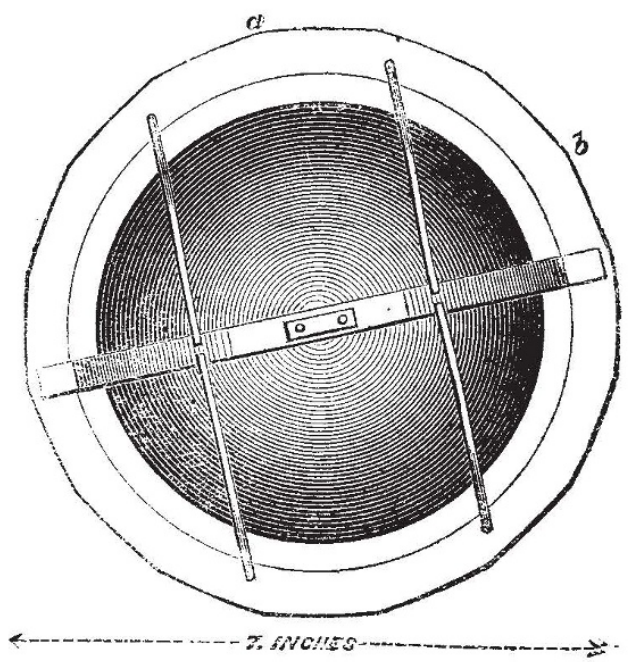

shell having its equatorial diameter about $3^{\frac{9}{0}}$ of its axial diameter, for the shell with axial diameter $\frac{9}{10}$ of equatorial diameter which was used when the apparatus was shown as a successful gyrostat.

$x$ In illustration of this see an exhaustive mathematical paper on the values of iron ores, by Prof. A. Habets: Cusper's Revue Universclle des Mines

$(x 877), t$. i. P. 504 .
2 By Sir William Thomson, F. R.S. British Association, Swansea, Section A. 
The oblate and prolate shells were each of them made from the two hemispheres of sheet copper which plumbers solder together to make their globular floaters. By a littie hammering it is easy to alter the hemispheres to the proper shapes to make either the prolate or the oblate figure.

Theory had pointed out that the rotation of a liquid in a rigid shell of oval figure, being a configuration of maximum energy for given vorticity, would be unstable if the containing vessel is left to itself supported on imperfectly elastic supports, although it would be stable if the vessel were held absolutely fixed, or borne by perfectly elastic supports, or left to itself in space unacted on

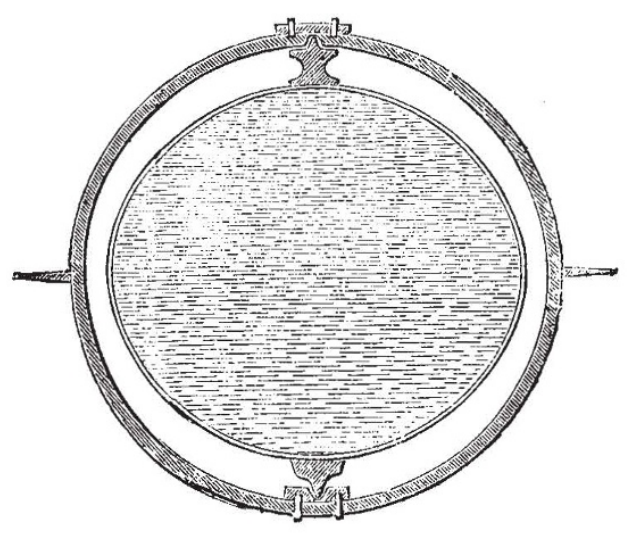

by external force; and it was to illustrate this theory that the cyal shell was made and filled with water and placed in the apparatus. The result of the first trial was literally startling, although it ought not to have been so, as it was merely a realisatien of what had been anticipated by theory. The framework was held as firmly as possible by one person with his two hands, keeping it as steady as he could. The spinning by means of a fine cord ${ }^{1}$ round a small $\mathrm{V}$ pulley of $\frac{1}{3}$-inch diameter on the axis of the oval shell, and passing round a large fly-wheel of 3 feet diameter turned at the rate of about one round per sicond, was continued for several minutes. This in the case of the oblate shell, as was known from previous experiments, would have given amply sufficient rotation to the contained water to cause the apparatus to act with great firmness like a solid gyrostat. In the first experiment with the oval shell the shell was seen to be rotating with great velocity during the last minute of the spinning; but the moment it was released from the cord, and when, ho!ding the framework in my hands, I commenced carrying it towards the horizontal glass table to test its gyrostatic quality, the framework which I he'd in my hands gave a violent niacontrollable lurch, and in a few seconds the shell stopped turning. I saw that one of the pivots had become bent over, by yielding of the copper shell in the neighbourhood of the stiff pivot-carrying disk, soldered to it, showing that the liquid had exerted a very strong couple against its containing shell, in a plane through the axis, the effort to resist which by my hands had bent the pivot. The shell was refitted with more strongly attached pivots, and the experiment has been repeated several times. In every case a decided uneasiness of the framework is perceived by the person holding it in his hands during the suning; and as soon as the cord is cut and the person holding it carries it towards the experimental table, the framework bagins, as it were, to wriggle round in his hands, and by the time the framework is placed on the table the rotation is nearly all gone. Its utter failure as a gyrostat is precisely what was expected from the theory, and presents a truly wonderful contrast from what is obierved with the apparatus and operations in every respect similar, except having an oblate instead of a prolate shell to contain the liquid.

I Instead of using a long cord first w. und on a bobbin, and finally wound up in the circumference of the large wheel as described in NATURE, February $x, 1877$, p. 297 , I have since found it much more convenient to use an endless cord little more than half round the crrcumference of the large wheel, and less than half round the circumference of the $V$ pulley of the gyrustat: and $t$, keep it tight enough to exert whatever tangential torce on the $\mathrm{V}$ pulley is desired by the ferson holding the framework in his hand. After continuing the spinning by turning the fly-wheel for as long a time as is judged proper, the endless cyrd is cut with a pair of sciscors and the gyrostat released.

\section{ON A DISTURBING INFINITY IN LORD RAYLEIGH'S SOLUTION FOR WAVES IN A PLANE VORTEX STRATUM}

IN the paper in last week's NATURE under this heading by Sir William Thomson, the lower part of the illustration was inadvertently turned round at the last moment by the printer ; the cut should stand as follows :-
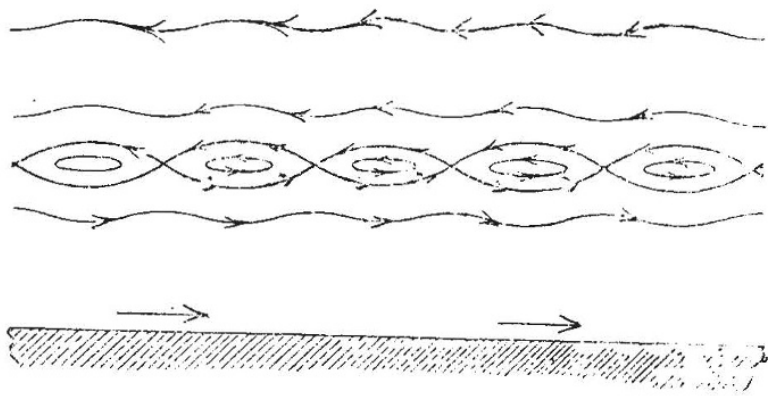

\section{SARGASSL:M 1}

THIS paper opens with a discuscion of the value of the species Sargassum bacciferum, the particular species of this genus which is well known as the Gulf-weed. The author considers that the floating plants to which this namej has been given are simply fragments of many varieties or species of Sargassum, more particularly of $S$. vulgare. In support of this; view he points out that, from the accounts of nearly all authors who have examined specimens, it appears that the lower part of the stem had been broken across, and that it is therefore fair to conclude that they belong to plants which are rooted under ordinary circumstances. This conclusion had been already arrived at by Rumphius, C. Agardh, Rennell, Humboldt, and more recently by G. von Martens; but of the e writers Iiennell and Humboldt are of opinion that the floating fragments continue to grow, and in this they agree with Thunberg, Meyen, and Harvey. Dr. Kuntze contends that there is not sufficient evidence forthcoming to establish the correctness of this view. He urge; that, even admitting that some growth takes place, it is only temporary, and that it therefore affords no ground for regarding these as pelagic plants. The only other cases of growth of Fuci when floating are offered by Macrocystis pyrifera (Sir Joseph (Mr. Moseley, "Notes by a Naturalist ond by Fucus vesiculosus doubtless Dr. "Notes by a Naturalist on the Challenger"), and question naturally arises as to whether these floating plants are actively living, or are dying, or dead.

In the case of Sargassum Dr. Kur tze considers that their bright yellow colour is due to changes taking place, either preliminary to or in consequence of deatb, in the brown colouring-mat:er of the attached forms to which he believes the floating fragments belong. Mr. Moseley, however, is of opinion that this is the natural colour of these plants whilst living. It does not appear that any such difference in colour has been noticed in attached and floating specimens of Macrocystis or of Fucus, and this is a fact which is not in harmony with Dr. Kuntze's views respecting Sargassum. Again, the general ob:ervation that these floating Fuci have no reproductive nrgans offers a further difficulty which they do not explain. Dr. Kuntze endeavours to meet the diffi. culty by stating that he has found receptacles occasionally in free-swimming individuals, and he gives figures of two plants bearing them; but neither from the fizures nor from his account of them is it possible to conclude with certainty that the bodie: in question are really of a repruductive nature; and he explains the usual absence of the e organs in the floating individuals by suggesting that the receptacles, being the most fragile parts of the plant, are the most readily destroyed, and further that, owing to the small number of air-chambers with which they are provided, they would sink on becoming detached. In this case, as in that of the colour, these explanations respecting Sargassum will only become valid when they are found to hold good of Macrocystis and of Fucus also. It is apparent that the

$x$ "Revision von Sargas-um und das sogenannte Sargasso-Meer." Von Dr. Otto Kuntze (Engler's botanische faibrbïcher, Bd. i. Heft iii., I $8 \&$ ). Leipzig, Engelmarn.) 